\title{
Young People in African (Agricultural) Policy Processes? What National Youth Policies Can Tell Us
}

\author{
Dolf J.H. te Lintelo
}

Abstract The 'youth in agriculture problem' makes up part of a growing set of 'youth in development' issues occupying the minds of aid practitioners and bilateral and multilateral donors. Aid agendas seek to enhance youth participation in policy processes and mainstream youth-related goals on health, education, employment and governance into development policies. Yet, these agendas routinely ignore national youth policies (NYPs), which in many African countries have been in place for well over a decade. This article demonstrates how NYPs in Nigeria, Tanzania and Zambia express distinct policy visions, identifications and imaginations of the youth 'problematique', and particular philosophies of intervention. It argues that while their substantive content may well be subject to dialogue and reform, NYPs also express conceptualisations of the policy process and roles for knowledge, evidence and collective action that sit uneasily with new donor agendas, and are less amenable to change.

\section{Introduction}

Demographic change, persistent and disproportionate unemployment and their feared implications for political disorder are key drivers of growing donor attention to youth as a development category. Bilateral and multilateral donors thus increasingly seek to mainstream youth-related goals on health, education, employment and governance into development policies that cater to youth needs and aspirations (GSDRC 2011). While youth participation in policy processes has potential to channel their energy, passions and frustrations, it often turns out to be deficient, tokenistic, or too episodic to be meaningful (SPW/DFID-CSO 2010; GSDRC 2011; McGee and Greenhalf 2011). Donors thus increasingly seek mechanisms to enhance youth participation (GSDRC 2011), raising questions such as what is meaningful participation? How can voice be extended into influence? Who should participate, through what forms, and how can participation be appropriately institutionalised?

This article argues that answering these important questions will require donors to pay greater attention to existing national youth policies (NYPs). ${ }^{1}$ NYPs were established throughout Africa from the early 1980s, and have mushroomed since. They express African governments' ideas on youth development challenges, on how to address these, and suggest more or less explicit theories of change. This article analyses the NYPs of Tanzania, Nigeria and Zambia, whose selection was driven by availability of secondary material. It is recognised that in coming years, these policies are likely to be influenced by the African Union's African Youth Charter (African Union 2006), which became legally binding in 2010. The analysis of NYPs also provides a perspective on how African nations are likely to use policies to address a widely perceived 'youth in agriculture problem'. In a nutshell, this asserts that youth labour, energy and enterprise is essential to successful agricultural growth and transformation, yet young people lack motivation for a career in farming (Anyidoho et al. 2012).

The article analyses the NYPs with reference to contemporary debates on youth in policy processes, and focuses on two aspects of the policy environment. First, it analyses philosophies of intervention of the NYPs, through an assessment of target groups; roles

IDS Bulletin Volume 43 Number 6 November 2012 (c) 2012 The Author. IDS Bulletin (c) 2012 Institute of Development Studies Published by Blackwell Publishing Ltd, 9600 Garsington Road, Oxford OX4 2DQ, UK and 350 Main Street, Malden, MA 02148, USA 
assigned to urban and rural youth; the social construction of the 'youth development problem' and youth images. Second, it considers how policy documents assert particular models of the policy process, to suggest a propensity for particular forms of youth participation. Accordingly, I assess how NYPs incorporate normative and empirical perspectives on the policy process, in particular regarding the role of evidence, knowledge, expertise and collective action by state and non-state actors.

In the first section, the article discusses youth policies in international arenas to note the great variation in the ways in which youth is conceptualised and operationalised in policy and legislation. The next section explores policy discourses to assess assumptions that underpin youth policies in Nigeria, Tanzania and Zambia. I first summarise key debates in the international development community, and then analyse the philosophies of intervention of case country youth policies. Next, the article places the NYPs within the context of academic debates on youth participation. The last section reconnects the discussion to the theme of youth in agriculture.

\subsection{The growing momentum of youth policies in (inter)national arenas}

Although youth has been part of the

international community's policy agenda at least since 1965, it gained particular momentum from the mid-1980s onwards, with the UN declaring 1985 as the first International Year of Youth. The subsequent Millennium Development Goals (No 8) aim to integrate alienated youth in the global economy, and sets out 'Developing and implementing strategies for decent and productive work for youth' (target 16) (Chaaban 2009: 35). 2010 was declared another UN International Year of Youth, with the slogan 'Our youth, our voice'. Similarly, the African Union designated 2008 as the African Youth Year, and has declared 2009-19 as the decade of youth development (African Union 2011).

UN bodies like the ILO, UNDP, UNICEF and UNESCO have long encouraged national policymakers to cater to youth, promoting national youth policies as 'indispensable', a 'symbol of society's commitment to its young citizens' and as 'one of the highest priorities of society' (UNESCO 2004: 5, 6, 35). The African Union and regional bodies such as the East
African Community also increasingly aim to steer domestic youth policy agendas. For instance, Article 12 of the African Youth Charter (AYG) sets out that 'State Parties shall develop a comprehensive and coherent national youth policy' for subsequent enactment into law (African Union 2006). As the Charter was activated in August 2010, and with ratification processes ongoing in countries, the AYC can be expected to increasingly drive youth policy reforms.

\section{How policies identify youth}

Some consider that the creation of 'youth' as a category in Africa is a post-colonial phenomenon promoted by ministries of 'Youth Sports and Culture' and youth wings of political parties, while being nowadays further underwritten by a global consumption-oriented youth culture (Frederiksen 2010: 1078). Donor agencies consider youth a specific social category 'laden with risk and uncertainty' (UNESCO 2004: 6). Yet, for all its intuitive appeal, a clear distinction between youth, children and adults is less straightforward than it appears. A bewildering range of definitions and working definitions are used for youth, often organised around age but sometimes around alternative criteria, hindering comparative research.

Where youth is defined in age-based terms actual age ranges vary. The African Youth Charter considers youth as people between 15-35 years of age. The official UN definition of youth refers to people in the age bracket 15-24, which is followed by Tanzania and Zambia in their youth policies. Nigeria defines youths as persons of ages 18-35. Further, even within countries, administrative parts of the state do not necessarily define youth in the same way (Wallace and Bendit 2009). Thus, while legal systems depend on clear-cut definitions, legal minimum ages may vary by gender, and by purpose, for instance for marriage, voting rights, criminal responsibility, military service, access to alcoholic beverages, and consent to medical treatment or sexual intercourse. In Tanzania, the NYP considers people between 15-18 years of age as youth but its Children Development Policy considers this group as children (Government of Tanzania 1996a).

One drawback of age-based definitions is that they can be insensitive to culturally specific notions of youth, childhood and adulthood. Thus, 
"we cannot define children or childhood on the basis of age because a "child" is not the same everywhere. Childhood may be universal as a phenomenon but the position of a child is formed in relation to culturally and geographically specific institutions, traditions and forms of family life' (Kallio and Hakli 2010: 357). Moreover, even though youth's transitional nature is universally accepted (UNESCO 2004), transition processes and foci vary and are subject to change. While some donor agencies focus on particular transitions - for example, the transition from school into work (e.g. Garcia and Fares 2008; UNECA 2009) - this makes up only one part of a multilayered and often gendered transition to adulthood.

Sociological understandings highlight that a young person's transition to adulthood takes place on multiple axes (MacDonald et al. 2001), through 'boundary events' concerning: school/occupation, family/matrimony and citizenship (Lloyd 2006). However, such transitions are increasingly understood as being non-linear (UN 2005; Lloyd 2006), as the social, matrimonial, family, residential and citizenship factors that condition an individual's passage to adult life are more and more fluid. For instance, Lloyd notes that compared to the early 1990s, young people in developing countries are nowadays: entering adolescence earlier and healthier; more likely to spend their adolescence in school; more likely to delay marriage and childbearing; and more likely to have a postponed entry to the labour force. ${ }^{2}$ There is greater variety between individuals (or cohorts) than ever before, with highly individualised and fuzzy trajectories, that are often partial, iterative or delayed (Calves et al. 2009; Locke and te Lintelo (forthcoming)). For instance, a 36-yearold unemployed and unmarried Tanzanian man living with his parents may be seen as a 'youth', despite having passed the age range identified in the national youth policy.

Some national youth policy documents reference both an age-based and more culturally sensitive identification of youths. Tanzania employs an age-based working definition, but also explicitly recognises that youth concerns a transition period from childhood to adulthood. It acknowledges a variety of community-specific understandings of what youth entails, and notes that commonly, in this period, young people are expected to start participating in various development activities. Youth are expected to begin to show maturity in thought and reasoning, decisiveness in action, and gain a certain measure of self-reliance (Government of Tanzania 1996b). Its cultural sensitivity makes the policy potentially amenable to the growing fluidity in youth transitions.

While some youth policies identify target groups, recognising that youth are not homogenous, targeting often involves the identification of very broad categories. Nigerian policy thus lists as targets: students in post-primary schools; students in tertiary institutions; out-of-school, unemployed youth; female adolescents; youths with disabilities; youths with health problems and youths engaged in substance abuse, cultism and delinquency (Government of Nigeria 2001). The Government of Zambia (1994) identifies two priority groups: rural youths and the disabled (chapter 1.8). The Tanzanian youth policy (Government of Tanzania 1996b) does not identify specific priority targets, but directs the ministries to develop particular programmes. For instance, the Ministry of Agriculture is directed to prepare farming and livestock programmes (chapter 5.8.1) and to develop strategies to train youth in modern agriculture (5.8.2). More generally, it is important to note that youth policies have wellbeing rather than anti-poverty objectives, that is, they tend not to prioritise the poor.

\section{Youth policies: philosophies of intervention} In this section, I explore policy discourses on the nature of the problems to be addressed by youth development interventions. I first summarise key debates in the international development community, and then discuss issues identified in national youth policies.

\subsection{Problems, images, and policy aims}

(Inter)national youth policies typically discuss themes such as (sexual) health; employment; education; armed conflict; globalisation; poverty; culture, etc. (e.g. UN 2005; UNECA 2009). Increasingly, they highlight a role for youth in policy processes. However, the dominant issues identified concern the interlinkages of demography, unemployment and political insecurity.

The rapid and sustained increase in the number of young people in the global South is one of today's most significant demographic trends. Around 90 per cent of young people reside in 
developing countries (Shankar 2010). By 2030 Africa is projected to have as many youth as East Asia and by 2050 could also exceed the youth population in South Asia (Garcia and Fares 2008). Young people make up approximately 30 per cent of the total population in African countries, and this is increasing fast (Panday 2006), with concomitant growth in (even higher) shares of the working population. The growing number of young people entails a process of demographic change; societal 'rejuvenation' in a literal sense. For instance, in 2005, 76 per cent of the Zambian population were under 30 years of age, with those aged 20-29 years accounting for a mere 18 per cent (CSO 2007).

Whereas some commentators are pessimistic about the prospects for economic growth and poverty reduction in Africa (e.g. Collier 2008), youth bulges are recognised by many as a window of opportunity. They offer a demographic dividend: where a larger workforce with fewer dependents could generate strong economic growth (Garcia and Fares 2008; Gunatilake et al. 2010). Yet, experiences to date are mixed: while a conducive policy environment in East Asia harnessed the dividend to achieve strong growth, similar demographic dynamics in Latin America failed to yield better economic outcomes (Garcia and Fares 2008).

Youth bulges are, however, also associated with severe levels of unemployment, and youth are seen as among the 'most vulnerable and most powerless [groups] in labour markets' (YEN n.d.). Recent global economic crises have hit youth hardest (Shankar 2010) and their impacts are not even included in youth unemployment figures which already show that Africa, at 21 per cent, is more severely affected than the world at large (14 per cent) (UNECA 2005: 167-202). Ironically, while both the health and educational status of African youth are better than ever $\left(\right.$ Garcia and Fares 2008) ${ }^{3}$ the 'educated unemployed' has been identified as a new social category (Jeffrey 2008, 2010). Compared to adults, African young people have much higher unemployment rates and operate more in the informal economy on lower wages and in more precarious jobs (Keune and Monticone 2004).

Growing youth bulges and widespread unemployment are often associated with insecurity, urban social unrest and political instability (Urdal and Hoelscher 2009;

Frederiksen 2010). ${ }^{4}$ Thus, a 2003 UN Security

Council mission to West Africa reported that: 'In every county visited, the mission heard about the problem of unemployment, particularly among young people, and how this was a perennial source of instability in West Africa.' The 'Arab Spring' reaffirms perspectives on the threat of large numbers of unemployed and impoverished youth to prevailing political orders.

National youth policy discourses in Nigeria, Tanzania and Zambia dating from the 1990s, show the enduring appeal of such images. They situate analyses of youth needs, problems and responsibilities within contexts of societal change, political order, social breakdown and economic decline. Unemployment is a key concern, and the NYPs recognise that some groups are particularly at risk. For instance, in Tanzania and Zambia, 60-65 per cent of unemployed people are youth, with girls disproportionally affected. The Nigerian policy notes that one in three disabled people is a youth, and disability profoundly affects economic opportunities. The policies observe that although the majority of youth are based in rural areas, many migrate in search of urban livelihood opportunities, despite having limited education, capital, equipment and technical skills. ${ }^{5}$

Young people are portrayed as either passive clients of government services, as constrained decision-makers, or autonomous agents able to shape their own destinies (White and Wyn 1998, in Curtain 2001). The NYPs emphasise not only the first two, but also assert strong normative aspirations for young people. The Tanzanian policy (1996b) wants youth to assume responsibilities as citizens, parents and leaders (chapter 3.1), to support local communities, and to preserve Tanzanian culture (2.0). The Nigerian policy (2001, preface) considers youth as the 'only real hope for a great future... [their] energy, inventiveness, character and orientation define the pace of development and the security of a nation'.

In some cases, the policies acknowledge that young people are already living up to some of these expectations, such as taking on political leadership roles in Tanzania. Yet, in many cases, the policies portray youth as deficient, complicit victims failing to exercise a sufficient level of responsibility and they are therefore in need of 
protection by a paternalist state. Here, the nationbuilding narrative seems a particularly doubleedged sword, as it carries a strong normative load: unemployment is not just undesirable from a poverty or wellbeing perspective, but speaks of individuals' moral deficiency towards community and nation. In a context of extreme scarcity of jobs in the formal economy and tremendous competition for these in the informal economy, young people are thus doubly victimised.

Moreover, policies that strongly emphasise young people as deficient risk institutionalising such negative views (Checkoway 2011).

The NYPs note that it is not only young people who are failing to discharge their obligations. Parents, guardians and society at large are failing to protect a group characterised as at a 'tender age', having limited life skills and economic needs. The Tanzanian policy (1996b) thus emphasises that fast-changing economic, cultural and social environments drive rapid changes in youth aspirations, orientations, culture, values and lifestyles. Foreign culture (and 'modem technology') is seen as implicated in the decline of established community systems of youth upbringing and responsible parenthood. Zambian policy (Government of Zambia 1994) notes a lack of guidance, counselling, recreational facilities and disintegrating families. The Nigerian youth policy (2001) is particularly ambivalent. It offers a eulogy to youth as 'energetic, active and in the most productive phase of their life as citizens' but also considers them 'the most vulnerable segment of the population socioeconomically, emotionally, and in other respects' (chapter 1.2). The schizophrenic imagery sets up a policy that emphasises the need for handholding and a paternalistic promise of social engineering. Young people need to be protected from themselves. The policy thus seeks to 'inculcate... the virtues of patriotism, discipline, selfless service, honesty and integrity'; 'inculcate leadership and make youth socially responsible and accountable'; and conduct socialisation programmes, 'so that they can become good and productive citizens' (2.5). Similarly, in order to offset negative economic, social, political and cultural influences (3.3), Tanzanian policy (1996b) asserts the need for education and media messages that teach 'acceptable morals in accordance with the culture of Tanzanians' (5.6.6; 5.12.2). Such cultural conservatism involves a move by adults to reclaim youth who deliberately seek the modern as a relatively ungoverned space for exploration and expression (De Boeck and Honwana 2005).

Moreover, invoking traditional tenets at a time when youth transitions are increasingly untenable, and more and more fluid in practice, raises an important question: does youth policy risk reinforcing social stigma associated with incomplete transitions to adulthood?

Interestingly, youth policies also reference state failure. In Zambia's case, the NYP is presented as a response to the state's failure to produce jobs and foster economies in the wake of neoliberal structural adjustment. As in Tanzania, state retrenchment is seen as an important cause of youth unemployment, while youth services were cut simultaneously (Government of Zambia 1994). The Nigerian youth policy (2001) explicitly critiques two decades of military rule, noting that youth policy 'suffered tremendous neglect' and ineffective implementation (1.4). Remarkably, it argues that a weak policy environment has caused growing un(der)employment, youth crime, illness and reduced school enrolment (1.4).

Accordingly, the Nigerian state is situated at the very heart of youth development, as both cause and solution. This informs a strategic policy perspective that aims to empower youth to take charge of their own destiny (chapter 1.1), but in a disempowering top-down and highly directive manner. Young people are the passive recipient, it is 'being trained' (4.4.1), receiving moral and ethical instruction by religious and community leaders (6.3.1), and mobilised, rather than enabled or encouraged to mobilise themselves. Policy seeks to tap and channel youth energy, and to make youth active participants in the shaping of the destiny of the nation (chapter 1). The policy 'aims to correctly guide, adequately mobilize and fully integrate youth into the fabric of society to support the goal of national development'. Youth policies are thus as much about disciplining undesirable behaviour and attitudes as about developing skills, and advancing youth wellbeing.

\subsection{Conceptualising the policy process}

I now consider how national youth policies may tell us something about how policymakers envisage the policy process to function. I look at three dimensions: the role of knowledge and evidence; the role of collective action and advocacy; and the role of participation. I argue 
that the particular ways in which policymakers think about the nature of the policy process has important implications for the ways in which youth policies structure opportunities for and constrain meaningful youth participation.

The policy process literature identifies three distinct analytical approaches. The stages model essentially considers that the policy process is made up of a sequence or cycle of successive stages. Usually these are set out as: agenda setting; policy formation (policy formulation and decision-making); implementation, evaluation and termination. This model assumes a hierarchy, with a primacy of politics over, and its separation from administration (Hill and Hupe 2009). It posits the policy process as a rational and technocratic problem-solving exercise, where values are exogenous: thus, politicians decide, and the bureaucracy executes policy. Here, scientific knowledge is seen to allow politicians to make better decisions, that is, 'truth speaks to power'. Experts play a critical role as generators and conduits of appropriate knowledge. Higher quality and more robust knowledge generates better policy decisions, and the role of non-bureaucratic actors in shaping policy content is de-emphasised. It considers a quite strict separation of state and society - where the latter provides input through the election of politicians but is otherwise standing at a distance from the policy process. While this model has been much criticised for its empirical lack of fit, linearity and lack of explanatory potential (Howlett and Ramesh 1998; John 1998; Sabatier 2007), as a heuristic device it is widely used and is reflected in commonly held beliefs about the policy process (de Leon 1999; Hill 2009).

Yet, the stages model downplays the contested nature of policy processes. Alternative conceptualisations of the policy process emphasise the relationship between knowledge, power and policy; processes of bargaining; the social construction of policy problems and solutions through particular narratives, framings and discourses that are furthered by particular social and state actors, actor-networks and coalitions, and the roles of ideas, interests, values and beliefs in these. The Advocacy Coalitions Framework and a set of 'argumentative turn' or deliberative analyses have distinct epistemological positions, but both emphasise the interactions between state and societal actors throughout the policy process. They emphasise the role of collective action, and the ways in which civil society groups continuously aim to engage with and influence policy. Policy processes are thus not seen as involving the best technocratic decisions, but rather as involving contestation and power struggles. Whereas an advocacy coalition approach argues that these contestations need to be empirically established, a deliberative approach emphasises the normative requirement for the state to foster ongoing participation and actively involve non-state actors (Sabatier 1998, 1999; Burton 2006).

\section{Knowledge, evidence and collective action}

Good youth policy should be based on facts and research on young people rather than assumptions and speculation (European Youth Forum 2001), yet the collection of comparative high-quality data is hindered by the variation in definitions employed.

An assessment of the NYPs of the case countries does not provide sufficient material to allow strong conclusions on the role of evidence and knowledge. Some passages hint at a technocratic policy process perspective. Both Tanzanian and Nigerian policies offer a situational analysis of the nature of the youth development challenge. The Zambian policy (Government of Zambia 1994) does not, but recognises that its efforts have been 'seriously affected by lack of data to gauge with precision and certainty the nature, extent and magnitude of youth problems. There is insufficient disaggregated data useful for planning' (chapter 1.3). Similarly, the Tanzanian policy (1996b) acknowledges the importance of data for informing policy and planning, and plans for research and data collection on youth and youth activities (chapter 4.2.1). In Nigeria, universities and research institutes are to monitor and evaluate implementation of the National Youth Development Policy (chapter 6.7.2) to 'provide useful guidance' for policy review and 'enhance the process and machinery of implementation' (7.4). Such evidence supports a technocratic policy process, where: 'policy success depends on [good] programme/project formulation, implementation and co-ordination, all of which in turn depend on the institutional capacity of the implementation organisation' (Government of Zambia 1994, chapter 1.8).

NYPs also have fairly explicit visions on the role of non-state actors from the private sector and civil 
society in the policy process. Such actors are recognised and promoted, yet predominantly allocated roles as service deliverers rather than as active, independent contributors to policy deliberation, formulation and review. Thus, the Tanzanian policy (1996b) seeks to enable youth and community mobilisation for youth rights (chapter 3.2) yet is silent about youth associations engaging with the formulation or implementation of policy and programmes. It also notes that representatives of Youth Economic Groups will be involved in Youth Development Committees, but how these groups are composed, what they do and how they are involved is not clarified.

The Nigerian policy promotes fora for regular consultation between student unions and the school management (6.2.2), and encourages the formation of youth organisations to provide services and promote group-based activities for young people (chapters 6.2.2, 6.3.1, 2). Successful policy implementation 'depends very much on mutual cooperation, partnership and solidarity of action among the various stakeholders' and on their effective coordination (7.1). While this suggests a less stagist approach to collective action, the NYP nevertheless offers a dirigiste, topdown vision: 'the Federal government will provide direction and leadership, other stakeholders such as local and state governments, non-governmental organisations, and private-sector entities must play their assigned partnership roles' (6.1, emphasis added). Such assigned partnership roles not only suggest a limited critical contribution from nonstate partners, but also sit uneasily with discourses of participation that are prominent in international debates about youth in development.

Youth participation in policy processes is receiving more and more recognition, as a political right (SPW/DFID-CSO 2010) and for programming reasons (UNESCO 2004; YEN n.d.). It is seen as central to efforts at mainstreaming youth-related goals into donors' core development policy, both in sectoral interventions (education, employment, health, etc.) and governance challenges (SPW/DFIDCSO 2010; African Union 2011; GSDRC 2011). The African Youth Charter obliges state parties to take measures to guarantee youth participation in parliament and other decisionmaking bodies, ensure gender equality of access (Article 11) and to grant a right to actively participate in the design, implementation and evaluation of development strategies and policies (African Union 2006; Panday 2006).

Internationally, youth policies aim to develop strategies that 'help young people to make the right choices, protect them from exploitation and neglect and ensure their participation in all spheres of society' (UNESCO 2004: 6). Similarly, the policy aims of the case studies stress empowerment (Nigeria), realisation of rights, enhanced youth welfare and quality of life, opportunities for self-actualisation and human development (Tanzania, Nigeria and Zambia) and effective participation in (national) socioeconomic development (Tanzania, Nigeria).

Arguments in favour of youth participation intertwine normative and empirical elements. There is a clear need to gain a stronger empirical understanding of youth participation in policy processes, not least because mass media, social science, and professional practice tend to emphasise their deficiencies and disengagement (Checkoway 2011). Few independent evaluations have assessed youth participation and its impacts (UN 2003: 285) and information on basic indicators for international comparisons is not available.

Proponents of youth participation emphasise its potential to promote personal development, substantive knowledge and practical skills, facilitation of the exercise of civic rights, and contributions to a more democratic society (UN 2003, 2005; Checkoway 2011; YEN n.d.).

Participation may improve policy processes by bringing a 'user perspective' (young people's knowledge, experience and commitment) to policy issues (UN 2003; Williamson 2007; SPW/DFID-CSO 2010; YEN n.d.). It enhances policy ownership, legitimacy and durability and promotes youth integration (UNESCO 2004) and thus benefits both young people and society at large by contributing to economic and social development (UN 2003).

As social actors with skills, drive and capacities, young people should be seen as part of the solution to the difficulties they face. They can draw on a unique body of experience and a tremendous amount of energy, passion and creativity (UN 2003; Yeo 2008; YEN n.d.). Failure to do so risks weak policy because of a disconnect between the life-worlds and life experiences of 
adult decision-makers and youth (UN 2003), particularly as migration, mobility and a greater variety of youth lifestyles generate growing complexity. Some have accordingly called for a more representative bureaucracy (Yeo 2008). Finally, the argument is advanced that a failure to enhance youth participation in policy processes risks policy failure, crime, violence and intergenerational discord (YEN n.d.).

Agreement on the need for participation is one thing, consensus on its purpose and forms, another. Is participation about 'community service,' or 'social action,' or 'civic engagement' (Checkoway 2011: 340)? The UN General Assembly defines (and encourages) youth participation as involving: economic participation, relating to work and development; social participation, relating to community involvement; cultural participation, relating to the arts, cultural values and expression; and political participation, relating to decisionmaking processes. These four elements are reaffirmed in the United Nations Convention on the Rights of the Child (1989), which promotes the principle that children and young people ${ }^{6}$ are entitled to express (and have taken seriously) their views on all matters that affect them. Article 12 sets out participation as a procedural right to take part in and influence processes, decisions and activities (UN 2003).

Often, youth participation is presented as a 'citizen-making device', teaching (moral) responsibility, civic values, human rights, and an encouragement to 'become active members of a democratic society' (McGee and Greenhalf 2011; YEN n.d.: 11). The NYPs studied also use such rhetoric, and the African Youth Charter expresses a republican notion of citizenship. It sets out a 'social contract between the State and the Youths' that 'addresses the rights and obligations of young people' towards their families, society and the state. Yet, the emphasis on citizenship development has a discriminatory tinge - after all, such demands are rarely made on adults. Emphasising citizenship deficiencies hence may perversely legitimate young people's unequal treatment.

While there are no shortages of positive examples, too often youth policy and legislation remains piecemeal (UNESCO 2004) and involvement in policy processes marginal (YEN n.d.). Few countries have made youth participation an integral aspect of national politics and policy processes (UNESCO 2004). Where they have, more accountability and transparency is needed on how suggestions in youth participation forums are acted upon (Yeo 2008).

Nevertheless, a growing number and variety of institutional forms provide 'spaces of participation', enabling exchange between generations, languages, cultural groups and religions (UNESCO 2004). National Youth Councils (umbrella organisations for youth organisations) have been set up in over a $100 \mathrm{UN}$ member states, sometimes as a statutory body (e.g. in Uganda and Malawi). Youth boards, associations, networks, NGOs and other forms operate across sub-Saharan Africa. Nigeria created a Youth Parliament in 2008, which is to be replicated across the 36 states and 774 local governments (Commonwealth Secretariat 2010). The government of Tanzania is in the process of developing a national youth participation strategy and also reserves ten seats in parliament for the youth wing of the leading Chama Cha Mapinduzi (CGM) party (Dahl Jensen 2010).

Successful institutionalisation of processes which bring youth and decision-makers together has significant advantages over informal and ad hoc consultations, as they help to build mutual trust and inspire constructive engagement (YEN n.d.). Besides platforms for exchange, institutionalisation may also take the form of the allocation of a proportion of relevant budgets to youth development; the systematic application of a youth assets rather than youth problems perspective across policies; regular monitoring, data collection and reporting of youth development efforts, outputs and outcomes (SPW/DFID-CSO 2010).

Yet, questions about appropriate and meaningful youth participation remain and key lessons from critiques on the participation turn in development (such as the need to consider power dynamics) are often ignored. In some countries, National Youth Councils are key stakeholders in decision-making on youth issues, in others they have purely symbolic status (UNICEF 2010), or are dysfunctional. Dependence on state funding makes youth councils vulnerable to political interference (Maguire 2007: 34; YEN n.d.). In Tanzania, the National Youth Council was never 
functional due to a civil society boycott in protest to its membership being dominated by youth wing members of the leading political party (Dahl Jensen 2010). More so, the decentralised Youth Development Committees at regional, district, ward and village levels that were to coordinate NYP implementation efforts were dominated by non-youth. One unanswered question then is under which conditions innovative forms of governance can become institutionalised.

Moreover, questions remain about the nature of participation, and who participates. By artificially clustering a wide variety of young people with diverse needs, desires and problems, the 'youth' terminology involves a serious oversimplification, and policy risks becoming insensitive to difference such as gender, class, geographic location, etc. For instance, poor young Africans face diverse sources of marginalisation. Poverty and youth often intersect with identity aspects (ascribed or otherwise) that confer disadvantage, such as gender; rural residence; ethnicity/caste; disability or being a migrant (SPW/DFID-CSO 2010: 8-9). Diverse youth representation in participatory forums hence is by no means assured. Resource constraints and logistical considerations often mean youth consultations have a strong urban bias, while proceedings may only be conducted in the official administrative languages. Consequently, the views of rural and uneducated poor youth (and other subgroups) may not be heard.

Youth leadership is often fragmented, uncoordinated, and in mainstream civil society tends to be composed of well-educated men, with limited experience and understanding of marginalised urban youth needs. Such leaders are unlikely to represent the views and needs of the non-elite, under-educated youth majority (Sommers 2010). Youth movements thus risk replicating the approach of many adult organisations in working for rather than empowering disadvantaged young people (UN 2003).

Perhaps no population group is more at risk, as well as overlooked, than adolescent girls and young women. The relatively few youth programmes and organisations that exist are dominated by male youth, while existing women's programmes and organisations are often dominated by more senior women
(Sommers 2006). Marginalised female youth are under-represented in all forms of civil society, while marginalised male youth may be involved in forms of civil society distinct from mainstream forms (Sommers 2010). This is partially because of a strong 'youth and political disorder' discourse; even in donor programming 'vigilance is needed to ensure that 'youth' does not start to mean only boys and young men' (Maguire 2007).

\section{1 'Participation-light': sociocultural and institutional factors}

National youth policies in the case countries adopt a 'participation-light' approach. They suffer from weaknesses common to participatory development discourses (Cooke and Kothari 2001). NYPs pay little attention to political participation, integration into adult society, and fostering youth autonomy and fail to develop meaningful forms of participation that can help to bring about youth engagement in policy processes on their own terms. Tanzania thus argues for participation, but not as a cross-cutting imperative (only in a few ministries), and not in village government, and suggests its purpose is to prepare youth for leadership roles. The Zambian NYP argues for national, not local youth advocacy. The Nigerian NYP aims to involve youths in decision-making at all levels of government in all matters affecting them (chapter 2.5). It was produced through nationwide consultations with youth organisations, administrators and NGOs through Zonal Youth Summits and is monitored by five-yearly reviews involving young people. Nevertheless, the policy exudes a strong top-down ethos and a very passive role for youth, which sits uneasily with a more substantial form of participation.

Having voice hence does not necessarily translate as having influence. Indeed, often 'youth advocacy' is constructed as a process in which adults represent the interests of youth without any mechanisms of accountability to young people themselves (Checkoway et al. 2005: 1158). Young people often view engagement in governance processes as flawed: they feel treated as a 'token' young person, condescended to and being present but not heard (McGee and Greenhalf 2011: 22). This incentivises withdrawal, but also risks reinforcing negative perceptions of piecemeal youth engagement (SPW/DFID-CSO 2010). Moreover, the issues expressed by young people may be the ones given 
to them by adults, such as parents and teachers. In contrast, when young people identify their own issues it can inspire and move them into action. After all, 'young people are experts on being young people, regardless of what others think' (Checkoway 2011: 342).

Also, government officials with direct experience of working with young people are often more open to involving them in decision-making processes (McGee and Greenhalf 2011).

Nevertheless, entrenched sociocultural norms can systematically devalue young people's participation in decision-making. Notions that emphasise a close relationship between seniority and authority militate against more egalitarian notions that underpin the argument for youth participation in policy processes. In particular, respecting the right of 15-18-year-olds represents an enormous challenge to traditional attitudes in most highly patriarchal or highly stratified societies (UN 2003; YEN n.d.). Adults may see themselves as somehow better than youth because of their age and therefore feel entitled to act upon them. Assumptions about youth as immature, unproductive and ignorant constrain young people's access to decisionmaking spaces (McGee and Greenhalf 2011). Adult authorities' fear of youth can also undermine public participation (Checkoway 2011). In Tanzania, a culture of not speaking up is an important obstacle to young women's participation in decision-making, from the family to the public sphere (Dahl Jensen 2010).

Engrained attitudes to policy processes as expert-driven also tend to devalue young people's inputs (YEN n.d.).

It is not unusual that participation in public affairs attracts particular youth groups. Many studies note that young people are uninvolved or minimally involved, while small groups that are typically not representative of the general population are extremely active. Income, education, and socioeconomic status all tend to correlate positively with individual participation (Checkoway 2011). Limited education and training inadequately equips young people to confidently participate in decision-making, and this is exacerbated by social exclusion and inequality (Maguire 2007; SPW/DFID-CSO 2010). While lower income people may participate less than higher income people in formal politics, this should not be interpreted as disengagement from democracy. Rather, it should be noted that the poor tend to participate in ways that are more appropriate to their situation (Checkoway 2011). As such, it would be interesting to assess whether and how poor youngsters are involved in social accountability mechanisms, which are an increasingly popular response to disillusionment with formal accountability mechanisms (McGee and Greenhalf 2011).

Besides sociocultural factors, institutional features of the polity influence which youth participate. Givil society in African countries enjoys substantial variation in political freedoms, and this frames the possible and realised organisational shapes that youth participation may take. In Tanzania for instance, the 2002 NGO Act makes critical youth groups vulnerable to censorship, and they thus have to very carefully navigate government sensitivities when expressing political or policy critiques (Dahl Jensen 2010). Some young people lack access to the processes through which adults can articulate their concerns. Very few countries give 15-18-year-olds voting rights. Moreover, youth lack access to the courts and the media, while trade unions and professional associations often focus on the formal economy, in which few young people are employed (UN 2003; Maguire 2007).

Supportive, coordinated legal and policy frameworks are thus key to enhancing meaningful youth participation and to foster youth as partners and leaders in development (SPW/DFID-CSO 2010). They should support young people's skills, capabilities and capacity to act on their own lives, and aim to remove barriers to their agency, which are generated and maintained by social power inequities. Above all, effective strategies empower youth, in all their diversity, to autonomously and actively influence and shape the political agenda (Checkoway 2011). This requires decision-makers to develop policy and programmes for the benefit of youth (as beneficiaries), with youth (as partners), and be shaped by youth (as leaders) (SPW/DFID-CSO 2010: 3). ${ }^{8}$ Such policies can legitimately employ diverse, culturally sensitive and age appropriate forms of participation (Checkoway 2011).

Overcoming obstacles to meaningful youth participation hence requires transforming values, and fostering self-esteem and confidence. 
Meaningful participation requires equal opportunities; proper resourcing; and may be institutionalised through participation policies and standards (SPW/DFID-CSO 2010). ${ }^{9}$ It is an ongoing process, involving information sharing, consultation, decision-making and initiating action, with an aim to progress from consultation and dialogue towards engagement in the planning, implementation and co-management of development interventions (SPW/DFID-CSO 2010). High-quality youth programmes are characterised by effective alliances of youth leaders and adult allies. The former serve as bridging persons across generational boundaries, while adults can reach out, nurture young people's ideas, and build support for their work (Checkoway 2011). Youth policies should thus increasingly enable young people to organise around issues of their choice, enable adults to engage young people in community agencies, and enable youth and adults to join together in intergenerational partnerships (Checkoway et al. 2005). This requires building both the capacity of young people to engage with adults ${ }^{10}$ and the capacity of adults to foster youth-adult partnerships (SPW/DFID-GSO 2010; UNDESA 2010). 'Until more non-youth leaders turn to the youth as equitable partners... youth involvement will be limited to unproductive demonstrations instead of powerful movements' (Fredericks 2010).

\section{Conclusion}

Demographic change, persistent and disproportionate unemployment and their feared implications for political disorder are key drivers of growing government and donor attention to youth as a development category. The recognition that development policies, strategies and programmes must cater to young people has been accompanied by a clarion call for appropriate institutional forms and practices that can foster more substantial youth participation in decisionmaking processes. This article argues that greater attention needs to be paid to existing national youth policies. NYPs express African governments' ideas on the youth development challenges, on how to address these, and suggest more or less explicit theories of change. They hence provide a broad framework for discussions on 'youth in agriculture'. Accordingly I have analysed national youth policies in Nigeria, Tanzania and Zambia, for both content, and for the ways in which they assert particular models of the policy process.
Youth policies have wellbeing rather than antipoverty objectives, that is, they tend not to prioritise the poor. While it is fine for policy to generically frame youth problems, needs and solutions, programmatic efforts need to be much more sensitive to difference (gender, ethnicity, etc.). Currently, the NYPs are 'underoperationalised' in this respect. Moreover, NYPs assert strong normative aspirations for young people, but also posit that their failure to live up to these and their inability to protect them from themselves legitimates paternalist state interventions. Although NYPs also identify social factors, they tend to situate the state at the heart of youth development, as both cause and solution. Where empowerment is sought, as in Nigerian policy, it is done in a disempowering top-down manner, with youth as passive recipients.

NYPs also tend to have a stagist conceptualisation of the policy process, with a technocratic view of evidence, limited roles for collective action and a 'participation-light' approach. Arguments about youth participation thus typically intertwine normative and empirical arguments regarding its effects. Disentangling these requires greater empirical enquiry. In terms of collective action, NYPs recognise and promote a role for private sector and civil society actors in policy processes, yet predominantly as service deliverers rather than as active, (semi-)independent contributors to policy deliberation, formulation and review. Youth themselves are also envisaged as passive clients of government services and seen as constrained decision-makers. They are rarely portrayed as or encouraged to be autonomous agents able to shape their own destinies.

The analysis of youth policies hence suggests several implications for the ways in which African states are likely to address the 'youth in agriculture problem'. As long as youth are seen as an undifferentiated and problematic mass that is to be acted upon, to be protected, reformed and directed, state action is likely to take a directive rather than facilitating form. Agricultural policies are thus likely to prescribe one-size-fits-all solutions (e.g. modernisation), that are insensitive to the varied needs and instrumental ways in which young people engage in agriculture (Okali and Sumberg, this IDS Bulletin). Moreover, while youth mainstreaming and reforms in youth policy content will continue 
in coming years, entrenched stagist perspectives on the policy process are likely to be more 'sticky'. Accordingly, participation of African

\section{Notes}

1 Youth issues also need to be addressed in other policies (e.g. poverty reduction strategy papers; education; employment; and sexual and reproductive health strategies).

2 There are also significant variations by gender (often, young men stay in school longer, achieve higher qualifications and start working later than women), and location (urban youth start working later and achieve higher educational attainment than rural youth) (Garcia and Fares 2008).

3 A notable exception is Zambia, where neoliberal reforms involved massive public disinvestment from education: the young in Zambia are now less educated than older groups.

4 Their study of 55 cities, however, rejects the argument that youth bulges and unemployment are likely to lead to political and social disturbances (Urdal and Hoelscher 2009).

5 Tanzania's 2001 agricultural sector development strategy also notes that migration from rural areas is increasingly problematic due to an absence of urban jobs (Dahl Jensen 2010).

6 The UNCRG covers children up to 18 years old.

\section{References}

African Union (2011) Roadmap to Implementing African Youth Charter, Addis Ababa: African Union

African Union (2006) African Youth Charter, Addis Ababa: African Union

Anyidoho, N.A.; Kayuni, H.; Ndungu, J.; Leavy, J.; Sall, M.; Tadele, G. and Sumberg, J (2012) Young People and Policy Narratives in Sub-Saharan Africa, FAC Working Paper 32, Brighton: Future Agricultures Consortium: 18

Burton, P. (2006) 'Modernising the Policy Process - Making Policy Research more Significant?', Policy Studies 27.3: 173-95

Calves, A.E.; Bozon, M.; Diagne, A. and Kuepie, M. (2009) 'Transition to Adulthood: Rethinking the Definition of First-Time Events', in P. Antoine and E. Lelievre (eds), Fuzzy States and Complex Trajectories: Observation, Modelization and Interpretation of Life Histories, Paris: Institut National Etudes Démographiques (INED): 121-37

Chaaban, J. (2009) 'Youth and Development in the Arab Countries: The Need for a Different Approach', Middle Eastern Studies 45.1: 33-55 youth in agricultural and other policies is likely to remain 'light' and continue to under-prioritise youth empowerment and autonomy.

7 For instance, Ghana and Kenya have a good record engaging young people in agricultural policy review processes such as CAADP and the African Peer Review Mechanism (Zimmermann et al. 2009: 220).

8 DFID has now adopted a 'three lens approach' to youth participation that works for the benefit of youth (as target beneficiaries), with youth as partners, and is shaped by youth as leaders (SPW/DFID-CSO 2010).

9 Some argue that 'institutionalizing collaboration requires the establishment of a formal relationship in which mutual rights and responsibilities are legally defined and social sanctions are imposed if such engagement fails to occur' (UNDESA 2010: 69).

10 Youth tend to have less experience in dealing with decision-makers, and can be easily intimidated by the structures and processes of governance. Youth from poor rural communities may speak a different dialect from the decision-makers or at least know that their accent 'lets them down'. For effective participation of youth, decisionmakers and youth themselves need education, experience and training (Maguire 2007).

Checkoway, B. (2011) 'What is Youth Participation?', Children and Youth Services Review 33.2: 340-5

Checkoway, B.; Allison, T. and Montoya, C. (2005) 'Youth Participation in Public Policy at the Municipal Level', Children and Youth Services Review 27.10: 1149-62

Collier, P. (2008) The Bottom Billion: Why the Poorest Countries are Failing and What Can Be Done About $I t$, New York: Oxford University Press

Commonwealth Secretariat (2010) Regional Senior Government Officials Meeting Report - Mid Term Review, Lusaka: Commonwealth Secretariat

Cooke, B. and Kothari, U. (eds) (2001) Participation: The New Tyranny?, London: Zed Books

CSO (2007) Labour Force Survey Report, Lusaka: Central Statistical Office, Republic of Zambia

Curtain, R. (2001) 'Youth and Employment: A Public Policy Perspective', Development Bulletin 55: 7-11

Dahl Jensen, C. (2010) Young People's Possibilities for Influence in Tanzania, Copenhagen: Konsulentnetværket 
De Boeck, F. and Honwana, A. (2005) 'Children and Youth in Africa: Agency, Identity, and Place', in A. Honwana and F. De Boeck (eds), Makers and Breakers. Children and Youth in Postcolonial Africa, Oxford: James Currey: 1-19 de Leon, P. (1999) 'The Stages Approach to the Policy Process. What has it Done? Where is it Going?', in P.A. Sabatier (ed.), Theories of the Policy Process, Boulder CO: Westview Press: 19-32

European Youth Forum (2001) 11 Indicators of a (National) Youth Policy, Brussels, www.un.org/esa/ socdev/unyin/documents/CoE_indicators.pdf (accessed 24 August 2012)

Fredericks, F. (2010) 'The Voices of Religious Youth: Are You Listening?', Huffington Post, 25 November, www.huffingtonpost.com/ frank-fredericks/the-voices-of-religiousy_b_610488.html (accessed 24 August 2012)

Frederiksen, B.F. (2010) 'Mungiki, Vernacular Organization and Political Society in Kenya', Development and Change 41.6: 1065-89

Garcia, M. and Fares, J. (eds) (2008) Youth in Africa's Labor Market, Washington DC: World Bank

Government of Nigeria (2001) National Youth Policy and Strategic Plan of Action, Abuja: Federal Republic of Nigeria

Government of Tanzania (1996a) Child Development Policy, Ministry of Community Development, Women Affairs and Children, Dar es Salaam, United Republic of Tanzania

Government of Tanzania (1996b) National Youth Development Policy, Ministry of Labour and Youth Development, Dar es Salaam, United Republic of Tanzania

Government of Zambia (1994) National Youth Policy, Lusaka, Zambia

GSDRC (2011) Helpdesk Research Report: Youth and Governance, Birmingham: Governance and Social Development Resource Centre, www.gsdrc.org/docs/open/HD760.pdf (accessed 24 August 2012)

Gunatilake, R.; Mayer, M. and Vodopivec, M. (eds) (2010) The Challenge of Youth Employment in Sri Lanka, Washington DC: World Bank

Hill, M. (2009) The Policy Process, Harlow UK: Pearson Longman

Hill, M. and Hupe, P. (2009) Policy Implementation, London: Sage

Howlett, M. and Ramesh, M. (1998) 'Policy Subsystem Configurations and Policy Change: Operationalizing the Postpositivist Analysis of the Politics of the Policy Process', Policy Studies Journal 26.3: 466-81
Jeffrey, C. (2010) 'Timepass: Youth, Class and Time in India', American Ethnologist 37.3: 465-81

Jeffrey, C. (2008) “"Generation Nowhere”: Rethinking Youth Through the Lens of Unemployed Young Men', Progress in Human Geography 32.6: 739-58

John, P. (1998) Analysing Public Policy, London: Pinter

Kallio, K.P. and Hakli, J. (2010) 'Political Geography in Childhood', Political Geography 29: 357-8

Keune, M. and Monticone, R. (2004) Improving Prospects for Young Women and Young Men in the World of Work: A Guide to Youth Employment, Geneva: International Labour Organization

Lloyd, C.B. (2006) Growing Up Global: The Changing Transitions to Adulthood in Developing Countries, Washington DC: National Research Council and Institute of Medicine of the National Academies

Locke, C. and te Lintelo, D.J.H. (forthcoming) 'Young Zambians "Waiting" for Opportunities and "Working Towards" Living Well: Lifecourse and Aspiration in Youth Transitions', Journal of International Development 24: 777-94

MacDonald, R.; Mason, P.; Shildrick, T.; Webster, C.; Johnston, L. and Ridley, R. (2001) 'Snakes and Ladders: In Defence of Studies of Youth Transition', Sociological Research Online 5.4

Maguire, S. (2007) Youth Mapping Study - DFID's Approach to Young People, London: Department for International Development (DFID)

McGee, R. and Greenhalf, J. (2011) 'Young Citizens: Youth and Participatory Governance in Africa', Participatory Learning and Action 64

Panday, S. (2006) 'African Youth Charter', HSRC Review, Pretoria: Human Sciences Research Council: 4

Sabatier, P.A. (ed.) (2007) Theories of the Policy Process, Boulder CO: Westview Press

Sabatier, P.A. (1999) 'The Advocacy Coalition Framework. An Assessment', in P.A. Sabatier (ed.), Theories of the Policy Process, Boulder CO: Westview Press: 117-166

Sabatier, P.A. (1998) 'The Advocacy Coalition Framework: Revisions and Relevance for Europe', Journal of European Public Policy 5.1: 98-130

Shankar, B. (2010) 'Global Economic Crisis Spurs Record Youth Unemployment: ILO', International Business Times, 16 August

Sommers, M. (2010) 'Urban Youth in Africa', Environment and Urbanization 22.2: 317-32 
Sommers, M. (2006) Fearing Africa's Young Men: The Case of Rwanda, Conflict Prevention and Reconstruction Working Papers Series, Washington DC: World Bank

SPW/DFID-CSO (2010) Youth Participation in Development: A Guide for Development Agencies and Policymakers, London: SPW/DFID-CSO Youth Working Group

UN (2005) World Youth Report, New York: United Nations

UN (2003) World Youth Report, Young People Today, and in 2015, ST/ESA/301, New York: United Nations

UNDESA (2010) World Programme of Action for Youth, New York: United Nations

UNECA (2009) African Youth Report. Expanding Opportunities for and with Young people in Africa, Addis Ababa: United Nations Economic Commission for Africa

UNECA (2005) Meeting Youth Unemployment Head On: Addressing Unemployment of Young People in Africa, Addis Ababa: United Nations Economic Commission for Africa

UNESCO (2004) Empowering Youth through National Policies, UNESCO

UNICEF (2010) Fact Sheet: Youth Participation, http://social.un.org/youthyear/docs/Fact\%20 Sheet\%20-\%20Youth\%20Participation.pdf (accessed 24 August 2012)
Urdal, H. and Hoelscher, K. (2009) Urban Youth Bulges and Social Disorder: An Empirical Study of Asian and Sub-Saharan African Cities, World Bank Policy Research Working Paper 5110, Washington DC: World Bank

Wallace, C. and Bendit, R. (2009) 'Youth Policies in Europe: Towards a Classification of Different Tendencies in Youth Policies in the European Union', Perspectives on European Politics and Society 10.3: 441-58

White, R. and Wyn, J. (1998) 'Youth Agency and Social Context', Australian and New Zealand Journal of Sociology 34.3: 23-38

Williamson, H. (2007) 'A Complex but Increasingly Coherent Journey? The Emergence of "Youth Policy" in Europe', Youth and Policy 95: 57-72

YEN (n.d.) Joining Forces with Young PeopleA Practical Guide to Collaboration for Youth Employment, Geneva: Youth Employment Network, International Labour Organization Yeo, N. (2008) Are You Listening? Youth Voices in Public Policy, Paris: Organisation for Economic Co-operation and Development

Zimmermann, R.; Brüntrup, M.; Kollavalli, S. and Flaherty, K. (2009) Agricultural Policies in Sub-Saharan Africa: Understanding CAADP and APRM Policy Processes, Bonn: German Development Institute 